\title{
Ambient temperature embrittlement of a Zr-based bulk metallic glass
}

\author{
F. Jiang ${ }^{\mathrm{a}, *}$, H.F. Wang ${ }^{\mathrm{a}}$, M.Q. Jiang ${ }^{\mathrm{b}}$, G. Li $^{\mathrm{a}}$, Y.L. Zhao ${ }^{\mathrm{a}}$, L. He ${ }^{\mathrm{a}}$, J. Sun $^{\mathrm{a}}$ \\ a State Key Laboratory for Mechanical Behavior of Materials, Xi'an Jiaotong University, Xi'an 710049, China \\ b State Kay Laboratory of Nonlinear Mechanics, Institute of Mechanics, Chinese Academy of Sciences, Beijing 100190, China
}

\section{A R T I C L E I N F O}

\section{Article history:}

Received 2 January 2012

Received in revised form 7 March 2012

Accepted 21 March 2012

Available online 12 April 2012

\section{Keywords:}

Bulk metallic glass

Strength

Plastic deformation ability

Ambient temperature

Embrittlement

\begin{abstract}
A B S T R A C T
Three-point bending experiments were performed on $\mathrm{Zr}_{52.5} \mathrm{Cu}_{17.9} \mathrm{Ni}_{14.6} \mathrm{Al}_{10} \mathrm{Ti}_{5}$ (Vit105) bulk metallic glass (BMGs) over a wide range of ambient temperatures varying from the liquid nitrogen temperature $(77 \mathrm{~K})$ to about boiling water temperature $(370 \mathrm{~K})$. The results demonstrated that the flexural strength of the $\mathrm{Zr}$ based BMG monotonously increased with decreasing of test temperature, whereas plastic deformation ability displayed a maximum at a moderate temperature (about room temperature). That is, the plastic deformation ability was deteriorated by either higher or lower temperature than room temperature through affecting shear band nucleation and propagation within materials respectively.
\end{abstract}

(c) 2012 Elsevier B.V. All rights reserved.

\section{Introduction}

Low-temperature mechanical behaviors of bulk metallic glasses (BMGs) have been attracted growing attentions due to potential applications such as space exploration, liquefied gas storage and cooling pipe of experimental thermonuclear reactor [1,2]. Similar to crystalline alloys, BMGs usually exhibit higher strength with the decrease of the ambient temperature [1-10]. Its underlying mechanism has been discussed in terms of shear transformation zones (STZs) $[1,3,5,10-12]$. On the other hand, the strengthened materials at low temperature usually behave more brittle. However, very interestingly, it is reported that BMGs at cryogenic temperature show enhanced plasticity in compression [1-8], even in tension $[9,10]$. Such plasticity improvement was attributed to multiple-nucleation of shear bands at low temperature [1,5,7]. Nevertheless, there are also some sporadic papers showing different trends [13-15]. Thus, one question naturally arises. Whether the plasticity of BMGs has monotone function of temperature like their strengths or not? The geometrical imperfections (i.e. miscut or non-orthogonal specimens) and the material's high sensitivity to the testing boundary conditions as well as low temperature, have great effects on the measured plastic strain during the compression test where the samples usually display large apparent compressive strain [16-19]. Thus, the three-point bending test is better to evaluate the plasticity of BMGs [20]. In this paper, we performed a series of three-point bending experiments on a Zr-based BMG over a wide

\footnotetext{
* Corresponding author. Tel.: +86 02982668173; fax: +86 02982663453.

E-mail address: jiangfeng@mail.xjtu.edu.cn (F. Jiang).
}

range of temperatures varying from the liquid nitrogen temperature $(77 \mathrm{~K})$ to near boiling water temperature $(370 \mathrm{~K})$. The variance of strength and plasticity of the BMGs with the temperature was investigated. The related mechanism is discussed as well.

\section{Experimental methods}

The master ingots of $\mathrm{Zr}_{52.5} \mathrm{Cu}_{17.9} \mathrm{Ni}_{14.6} \mathrm{Al}_{10} \mathrm{Ti}_{5}$ (Vit105) were produced by arc-melting $\mathrm{Zr}$ of $99.8 \%$ purity and $\mathrm{Cu}, \mathrm{Ni}, \mathrm{Al}$ and $\mathrm{Ti}$ of $99.99 \%$ purity in a Ti-gettered argon atmosphere. Plates with dimensions of $50 \mathrm{~mm} \times 20 \mathrm{~mm} \times 1.5 \mathrm{~mm}$ were prepared using the drop casting method. The glass transition temperature $\left(T_{\mathrm{g}}\right)$ of the Vit105 BMG is $683 \mathrm{~K}$ according to the DSC method at a heating rate $0.33 \mathrm{~K} / \mathrm{s}$. Three-point bending samples have the same dimensions of $20 \mathrm{~mm} \times 4 \mathrm{~mm} \times 0.8 \mathrm{~mm}$. The bending test was conducted on a computer-controlled SANS testing machine at a displacement rate of $0.02 \mathrm{~mm} / \mathrm{min}$. The span was $10 \mathrm{~mm}$. During testing, the loaddeflection $(P-\delta)$ curves were recorded. For the tests at above room temperature, the sample together with pushrod and supports was immersed in a silicon oil tank. The silicon oil was heated with a heater and a PT100 thermocouple was used to measure the exact testing temperatures at the time of testing. This procedure provided an accuracy of about $\pm 2 \mathrm{~K}$ at each temperature allowing for small temperature variations during testing time. During the cryogenic temperature test, the sample together with pushrod and supports was immersed in a cryogenic liquid tank. We adjusted the cooling mixtures with ethanol and liquid nitrogen or dry ice $\left(\mathrm{CO}_{2}\right)$ within the tank to achieve the desired temperature between $77 \mathrm{~K}$ (liquid nitrogen) and $273 \mathrm{~K} \mathrm{[21].} \mathrm{At} \mathrm{least} \mathrm{three} \mathrm{samples} \mathrm{were} \mathrm{tested} \mathrm{for}$ 
each case. After testing, a scanning electron microscope, SEM (JEOL Ltd JSM-6700F) was used to examine the bended samples.

\section{Results}

Fig. 1a presents the flexural stress-deflection $\left(\sigma_{b}-\delta\right)$ curves of the samples under three-point bending tests at different temperatures. Both flexural yield strength $\left(\sigma_{b, f}\right)$ and flexural modulus $\left(E_{b, f}\right)$ can be measured from above curves. Then we can plot the normalized flexural yield strength $\left(\sigma_{b f f} / E_{b f}\right)$ versus the normalized temperature $\left(T / T_{\mathrm{g}}\right)$ for the Vit105 BMG, shown in Fig. 1b. It can be seen that the strength increases with decreasing of the testing temperature. Johnson and Samwer [11] had put forward a universal criterion for plastic yielding of metallic glasses with a $\left(T / T_{\mathrm{g}}\right)^{2 / 3}$ temperature dependence. Here, it is apparent that $\sigma_{b f} / E_{b, f}$ and $T / T_{\mathrm{g}}$ also follows the criterion; their data (black panes in Fig. 1b) can be fitted by:

$\frac{\sigma_{b, f}}{E_{b, f}}=-0.00477\left(\frac{T}{T_{g}}\right)^{2 / 3}+0.03157$,

where the first term on the right hand denotes the strength softening due to temperature rise, the second term implies an extrapolating athermal strength of about $E_{b f} / 30$.

The plastic deflection values $\delta$ measured in Fig. 1a can be used to reflect their plastic deformation ability $[22,23]$. And the variation of the plastic deflection $\delta$ with the testing temperature $\left(T / T_{\mathrm{g}}\right)$ is shown in Fig. 1c as dark squares. It is very interesting to see that the

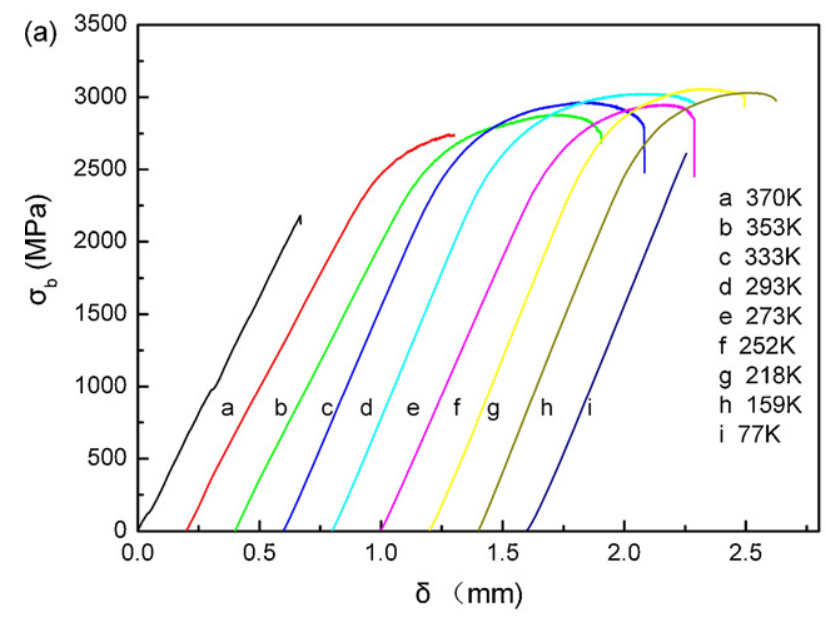

plasticity-temperature relationship does not obey a monotonous function. The plastic defection seems to achieve the maximum value at about room temperature, and decreases when the testing temperature is either lower or higher than the room temperature. In particular, the $77 \mathrm{~K}$ and $370 \mathrm{~K}$ tested samples exhibited no plastic deflection before failure. The observation indicates that the BMG samples show not only the low-temperature brittleness, but also the high-temperature brittleness. Actually, the latter has been observed previously by Lu et al. [24], and recently by Klaumunzer et al. [15].

The observed high-and-low-temperature brittleness can be further validated by SEM observations on shear band morphology on the tensile side surfaces and fracture pattern on resultant fracture planes. Fig. 2a-b, c-d, e-f, g-h and i-j correspond to the temperature $370 \mathrm{~K}, 353 \mathrm{~K}, 293 \mathrm{~K}, 159 \mathrm{~K}$ and $77 \mathrm{~K}$, respectively. The shear band density can also well reflect the plastic deformation ability because the plastic strain of BMGs mainly concentrates on shear bands [25]. The tensile side fracture surface of the sample consists of a smooth region and core-vein like region, as shown in Fig. 2(left column). It has been proposed that the smooth region was caused by shear sliding and the core-vein pattern was caused by subsequent catastrophic failure [26], where the serration (see the inserts) on the smooth region is due to the repeating melting and refreezing of shear layer [23], i.e. the stick-slip process [27,28]. The smooth region in the tensile fracture surface is corresponding to the critical shear displacement for crack nucleation occurred in shear bands [29-31]. This shear displacement is, to some extent, proportional to the plastic deflection [32]. The variations of

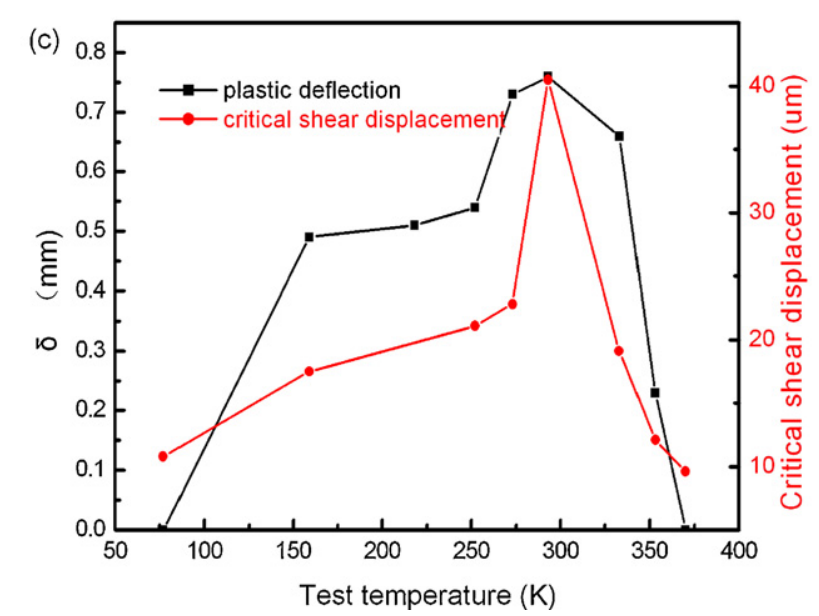

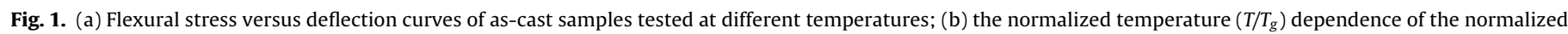
strength $\left(\sigma_{b f} / E_{b f}\right)$ for the studied alloy under bending; (c) variations of plastic deflection and critical shear displacement with the test temperature. 

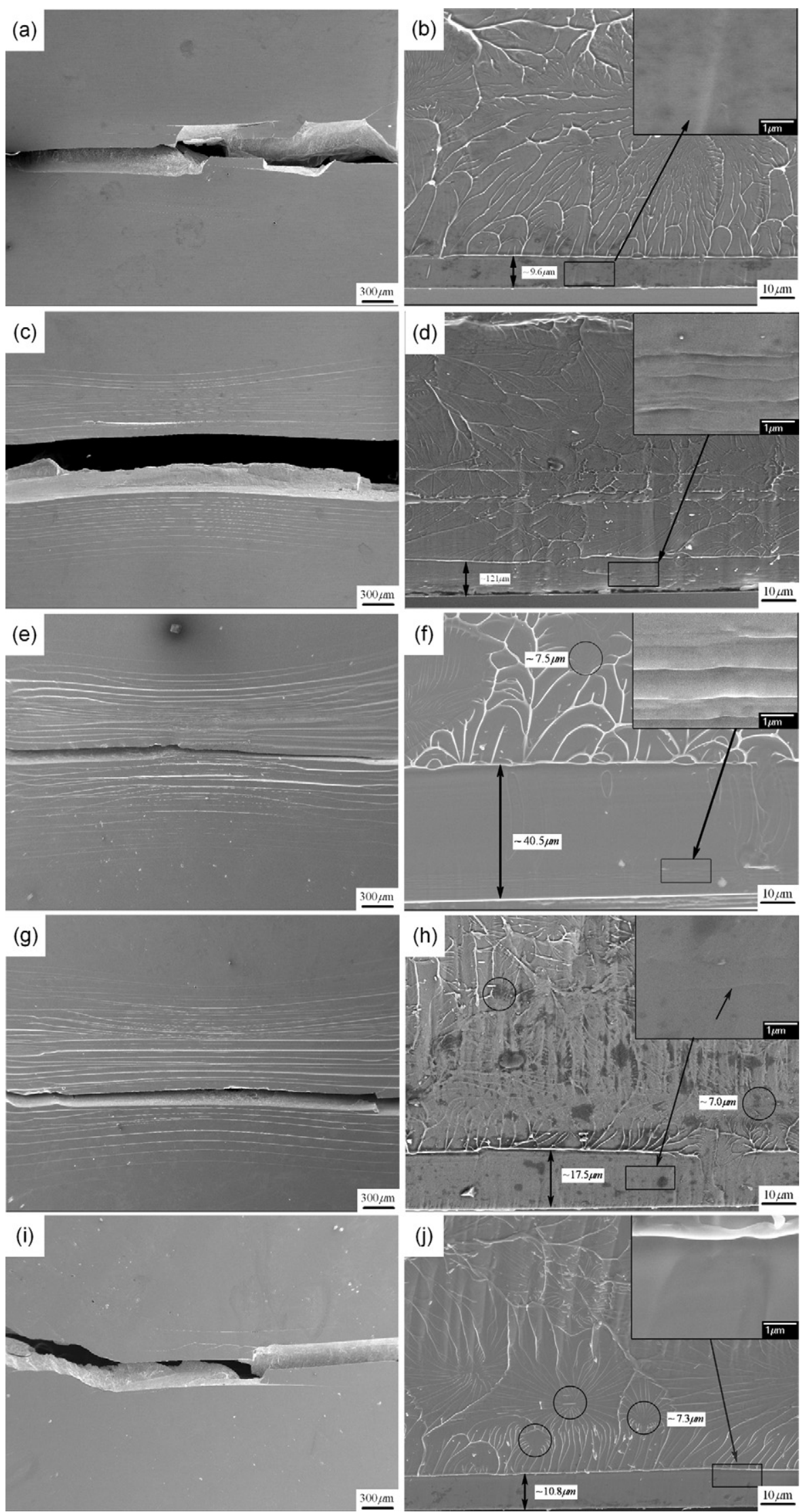

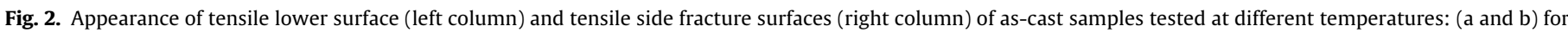
$370 \mathrm{~K}$, (c and d) for $353 \mathrm{~K}$. (e and f) for $293 \mathrm{~K}$, ( $\mathrm{g}$ and $\mathrm{h}$ ) for $159 \mathrm{~K}$, ( $\mathrm{i}$ and $\mathrm{j}$ ) for $77 \mathrm{~K}$. 


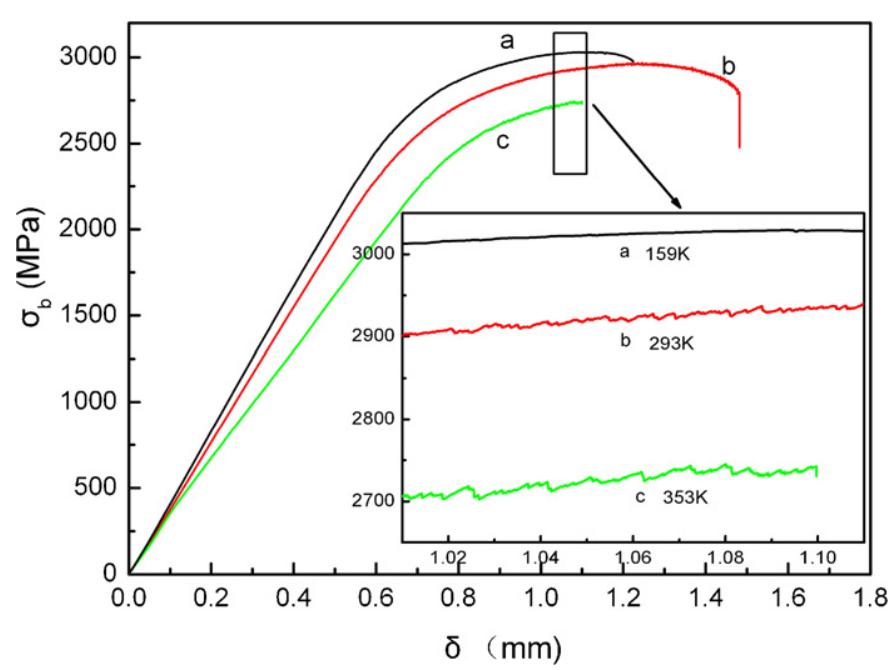

Fig. 3. Flexural stress versus deflection curves of $159 \mathrm{~K}, 293 \mathrm{~K}$ and $353 \mathrm{~K}$ tested samples, the inset is the enlarged portions of the serrated flows on the flexural stress-deflection curves, respectively.

measured critical shear displacement with the test temperature were also added into Fig. $1 \mathrm{c}$ as red dots. It is shown that the sample at $293 \mathrm{~K}$, i.e. room temperature, possesses the largest shear band density and the largest critical shear displacement. Either decreasing or increasing testing temperature will reduce both the shear band density and the critical shear displacement. This SEM observation is agreement well with the plastic deflection results (see Fig. 1). For example, the sample $293 \mathrm{~K}$ shows the densest shear bands (Fig. 2e) and the largest critical shear displacement of about $40.5 \mu \mathrm{m}$ (Fig. 2f), corresponding to the best plastic deformation ability with the plastic deflection of about $0.76 \mathrm{~mm}$. Comparing with room temperature tested samples, the $353 \mathrm{~K}$ tested sample exhibits reduced number of shear bands (Fig. 3c) and a smaller critical shear displacement of $12.1 \mu \mathrm{m}$ (Fig. 3d), corresponding to an inferior plastic deflection of $\sim 0.66 \mathrm{~mm}$ (Fig. 3b). The $370 \mathrm{~K}$ tested sample displays only one dominated shear band (Fig. 2a) and the smallest critical shear displacement of $9.6 \mu \mathrm{m}$ (Fig. 2b). Accordingly, the resultant macroscopic deformation only shows the elastic region without any ductility, as indicated in Fig. 1a. Similarly, with the decreasing of test temperature, the shear band density and critical shear displacement also reduced as shown in Fig. 2g, h (159 K) and $\mathrm{i}, \mathrm{j}(77 \mathrm{~K})$, respectively. Then, both the mechanical test results and the SEM observations demonstrate that the plastic deformation ability under bending does not monotonously increase with decreasing of tested temperature but displays a peak at a critical temperature. It should be addressed that, although the present samples will be brittle and display no plastic strain before failure both at cryogenic temperature and high temperature, their fracture surface were occupied mainly by micro-scaled core-vein like patterns rather than nano-scaled periodic corrugations [21]. We suggest that these samples still failed in a ductile shear mode rather than a brittle tensile mode, although they show no macroscopic plastic strain in their bending curves.

Additional, some samples were immersed in $370 \mathrm{~K}$ silicon oil and liquid nitrogen, respectively, for about $45 \mathrm{~min}$ which is similar with the duration of bending test. After this, those samples were tested at room temperature and found that theses samples could plastically deform same as the sample without subjected to higher temperature or low temperature. Moreover, bending test at $370 \mathrm{~K}$ was performed with the sample in water instead of silicon oil, the sample also failed without plastic deflection which is same as that in silicon oil. It is well established that, at temperatures below $0.8 T_{g}$, metallic glasses typically deform by flow localization such that all the plastic strain sustained by the sample is confined to narrow shear bands, at higher temperatures closer to $T_{g}$, metallic glasses can deform or creep homogeneously by diffusive processes controlled by the viscosity. For the most of $\mathrm{Zr}$ based metallic glasses, their $T_{g}$ usually are larger than $600 \mathrm{~K}$ but smaller than $800 \mathrm{~K}$, the present maximum test temperature $370 \mathrm{~K}$ is less than $0.8 T_{g}(480-640 \mathrm{~K})$ and these samples still deformed by flow localization as shear bands. Therefore, we suggested that embirttlement at cryogenic temperature and high temperature was mainly due to ambient temperature rather than other factors such as thermal annealing, cryogenic treatment or liquid medium, etc.

\section{Discussion}

It has been recognized that macroscopic flow of metallic glasses occurs as a result of a series of STZ operations to form shear band. The shear band consists of a layer of material with viscosity lower than that of the rest in the sample, which weakens the plane against fracture by the Taylor instability mechanism [33,34]. Once the viscous layer formed in the shear bands, the shear modulus will dramatically decrease, leading to lower resistance to applied stress and shear softening as is observed in the stress drop. At the same time, the released elastic energy stored in the metallic glass sample and testing machine system due to the stress drop can be transformed into heat to increase the temperature of shear layer and further decrease the viscosity of shear layer. If the energy release $\Gamma$ in a shear band overcoming the critical plastic energy $\Gamma_{c}$ [35-37] or the temperature rise in shear layer reaching a critical value $[28,38]$, shear band will not be arrested and failure of BMG samples will occur. Usually, elastic unloading of the stress [28], geometric constrainer [39] and friction from pushrod/material interface [40], etc. will cause a more pronounced deceleration of shear band. The local temperature at the shear band is given time to decrease, whereupon the viscosity of shear layer increases that introduces the re-freezing of the melt accompanying the stop of shear sliding [40]. Then it is well understood that the shear band propagation consisted of the acceleration, deceleration, and the final arrest, which is corresponding to the flow serration in the stress-strain curves [27,28,41]. If the shear band can be arrested, in response to the continued loading, the additional strain or displacement would be accommodated by initiating new shear bands to present more plastic displacement. Once the shear band nucleates and propagates, it becomes the weak site of the sample [39]. Furthermore, the shear-induced structural changes can lead to a situation where reactivation of the existing shear band is more favorable than initiation of new shear band [42]. Therefore, for the monolithic BMG under compression, the stable sliding along the formed shear band will continue due to the repeated melting and re-freezing, i.e. viscosity decreases with local melting, then increases as the material cools. While for the monolithic BMG under three-point bending, the new shear bands can initiate either at new sites on the surface or at the previous formed shear bands due to the existence of stress gradient [23,43]. Actually, the only difference between the compression and bending is that new shear band in the former tends to initiate from the previous formed shear banding, whereas in the latter is prone to form at either new or the previous sites.

The shear band is the carrier of plastic deformation of BMGs and total plastic displacement $(D)$ is the cumulation of individual plastic displacement $\left(V_{i}\right)$ from shear band, as follows:

$D=\sum_{i=1}^{n} V_{i}$

where $n$ denotes the number of shear bands during whole loading history before failure. 
On one hand, with the increasing of tested temperature, the temperature in the shear layer will not easily decrease, i.e. the shear-band velocity increasing [44] and the individual shear propagation process will cover larger displacement $V_{i}$ which means that the larger flow serration could be found in the $\left(\sigma_{b}-\delta\right)$ curves as shown in Fig. 3. However, the temperature rise in the shear layer will also be more prone to reach a critical value to induce failure. Then, the repeated numbers $n$ (i.e. shear band numbers) will be smaller, which is agreement with the SEM observation results of shear band density as shown in Fig. 2c. Accordingly, $D$ will be smaller and the samples show reduced plastic displacement. Above a critical temperature, the main shear band will not be arrested once propagating [15]. Then the sample fails quickly in brittle with only one dominant shear band left in the fracture sample surface as shown in Fig. 2a. At the same time, the serration region on the tensile side fracture surface also disappeared as shown in set of Fig. $2 \mathrm{~b}$, meaning no arrest of shear band. It should be noted that, the higher temperature will also facilitate the free volume accumulation to introduce nucleation of new shear bands easily (the yield strength decreases too). However, as previously suggested [23], the plasticity of BMGs was associated with two controlling factors, i.e. the arrest or pause of main shear band and the shear bands multiplication to provide more plastic strain. The former is dominant and is also the basis that the latter can take effect on enhancing the plasticity. Then the multiplication of shear band due to free volume easy accumulation will not be useful to the throughout plastic strain when the main shear band cannot be efficiently stopped.

On the other hand, at low temperature, the arrest of shear band is easy because the thermal conduction will help to decrease the energy release or promote the refreezing of the shear layer. However, the decrease of ambient temperature will impede the mobility of the free-volume zones and result in the enhanced activation energy of an STZ. In other words, the STZ requires the greater activation energy at lower temperatures, i.e. enhanced yield strength. Therefore, it is difficult to initiate new shear bands around the main shear band which are similar as the annealed sample with less free volume( ). Then reactivating new shear banding events on the formed shear bands would preferentially take place. The required strain or displacement by the test machine loading will mainly concentrate on the formed main shear band until failure occurs. Subsequently there will be fewer or even no shear bands on the tensile and compressive surfaces as shown in Fig. $2 \mathrm{i}$.

Since the higher temperature and lower temperature both deteriorate the plastic deformation ability, it is reasonable that the samples will present the best plastic strain at a moderate temperature where displacement $V_{i}$ maybe not larger but stable sliding will take place easily to produce larger number of shear band propagation process before failure, which is consistent with the present experimental results.

We also noticed the inconsistency between the reported enhanced compressive plasticity [1-8] and the reduced bending plasticity presented here in a certain range of cryogenic temperature. The enhanced compressive plasticity is generally believed to result from an intrinsic shear-band nucleation rate that increases with decreasing temperature $[1,5,7]$. However, very recently, Loeffler groups $[15,19,44]$ had suggested that the shearband propagation velocity obeyed an Arrhenius relation with temperature. The shear-band propagation velocity will decrease with the deceasing of temperature. In particular, at a critical temperature, shear-band velocity equals that of the cross-head velocity applied during the test, a shear band can be continuously driven at a defined rate in the absence of shear-band arrest and serration flow to accommodate all imposed strain via significant strain softening [19]. In other words, sliding along the principle shear band can be observed at the machine-driven rate under compression [8] to provide "good" plastic strain. Moreover, the enhanced stable plasticity from increasing shear-band nucleation rate and density is not an intrinsic property of the BMG but due to the geometrical constraints imposed by the deformation experiment [19]. For the bending, cryogenic temperature will also decrease the shear band velocity even to induce the shear band driven by machine pushrod without arrest, which can be identified by the absence of serration region on the tensile side fracture surface as shown in set of Fig. $2 \mathrm{j}$. Here, stable sliding along a dominant shear band at applied rate as under compression will not take place and immediately catastrophically fracture will occur to display poor plastic strain due to the geometric structure instability. It is addressed that systematic investigation on the plastic deformation ability of a Zr-based BMGs under compression over a wide range of ambient temperatures will be undertaken next. We also noted that the stress state alteration from plain strain to plain stress due to sample size [43] will have influence on the bending plasticity.

\section{Conclusion}

In summary, based on a series of three-point bending experiments on Vit105 BMGs over a wide range of temperatures varying from $77 \mathrm{~K}$ to about $370 \mathrm{~K}$, we found that the effect of ambient temperature on the flexural follows the $\left(T / T_{g}\right)^{2 / 3}$ softening law proposed by Johnson and Samwer. However, the plastic strain under the present bending tests does not show the monotone relationship with the ambient temperature, but appears a peak at a moderate temperature. In the vast majority of applications, bending is the prominent loading mode, with the sample subjected to both tensile and compressive stresses. Since lower and higher temperature (only boiling water temperature) will both deteriorate their plastic deformation ability through affecting shear band nucleation and propagation within materials respectively. More attention should be paid to the application of BMGs as structural materials.

\section{Acknowledgments}

The financial support from the National Natural Science Foundation of China (NSFC) under Grant Nos. 51171138, 51171137 and 11002144 are gratefully acknowledged. The work was supported by Ph.D. Programs Foundation of Ministry of Education of China (20110201110002). The authors also wish to express their special thanks for the support from the National Basic Research Program of China (Grant No. 2010CB631003).

\section{References}

[1] H.Q. Li, K.X. Tao, C. Fan, P.K. Liaw, H. Choo, Appl. Phys. Lett. 89 (2006) 041921.

[2] T. Okuno, A. Kawashima, H. Kurishita, W. Zhang, H. Kimura, A. Inoue, Mater. Trans. 49 (2008) 513.

[3] H.Q. Li, C. Fan, K.X. Tao, H. Choo, P.K. Liaw, Adv. Mater. 18 (2006) 752.

[4] A. Kawashima, T. Okuno, H. Kurishita, W. Zhang, H. Kimura, A. Inoue, Mater. Trans. 48 (2007) 2787.

[5] K.S. Yoon, M. Lee, E. Fleury, J.C. Lee, Acta Mater. 58 (2010) 5295.

[6] A. Kawashima, Y.Q. Zeng, M. Fukuhara, H. Kurishita, N. Nishiyama, H. Miki, A. Inoue, Mater. Sci. Eng. A 498 (2008) 475.

[7] Y.J. Huang, J. Shen, J.F. Sun, Z.F. Zhang, Mater. Sci. Eng. A 498 (2008) 203.

[8] A. Vinogradov, A. Lazarev, D.V. Louzguine-Luzgin, Y. Yokoyama, S. Li, A.R. Yavari, A. Inoue, Acta Mater. 58 (2010) 6736.

[9] A. Kawashima, Y. Yokoyama, I. Seki, H. Kurishita, M. Fukuhara, H. Kimura, A. Inoue, Mater. Trans. 50 (2009) 2685.

[10] L.S. Huo, H.Y. Bai, X.K. Xi, D.W. Ding, D.Q. Zhao, W.H. Wang, R.J. Huang, L.F. Li, J. Non-Cryst. Solids 357 (2011) 3088.

[11] W.L. Johnson, K. Samwer, Phys. Rev. Lett. 95 (2005) 195501.

[12] Y.Q. Cheng, E. Ma, Acta Mater. 59 (2011) 1800.

[13] E.d. Tabachnikova, A.V. Podol'skii, V.Z. Bengus, S.N. Smirnov, D.V. Luzgin, A. Inoue, Low Temp. Phys. 34 (2008) 675.

[14] V.Z. Bengus, E.D. Tabachnikova, J. Miskuf, K. Csach, V. Ocelik, W.L. Johnson, V.V. Molokanov, J. Mater. Sci. 35 (2000) 4449.

[15] D. Klaumunzer, R. Maaß, F.H. Dalla Torre, J.F. Loeffler, Appl. Phys. Lett. 96 (2010) 061901.

[16] W.F. Wu, Y. Li, C.A. Schuh, Philos. Mag. 88 (2008) 71. 
[17] K. Mondal, G. Kumar, T. Ohkubo, K. Oishi, T. Mukai, K. Hono, Philos. Mag. Lett. 87 (2007) 625.

[18] K. Mondal, K. Hono, Mater. Trans. 50 (2009) 152.

[19] R. Maaß, D. Klaumünzer, E.I. Preiß, P.M. Derlet, J.F. Loeffler, Scr. Mater. 66 (2012) 231.

[20] D.C. Hofmann, G. Duan, W.L. Johnson, Scr. Mater. 54 (2006) 1117.

[21] F. Jiang, M.Q. Jiang, H.F. Wang, Y.L. Zhao, L. He, J. Sun, Acta Mater. 59 (2011) 2057.

[22] F. Jiang, Z.B. Zhang, J. Zhang, L. He, J. Sun, Acta Metall. Sin. 42 (2005) 1031.

[23] L.C. Zhang, F.F. Jiang, Y.L. Zhao, S.B. Pan, L. He, J. Sun, J. Mater. Res. 25 (2010) 283.

[24] J. Lu, G. Ravichandran, W.L. Johnson, Acta Mater. 51 (2003) 3429.

[25] M.Q. Jiang, L.H. Dai, J. Mech. Phys. Solids 57 (2009) 1267.

[26] A. Inoue, T. Zhang, T. Masumoto, J. Non-Cryst. Solids 156/158 (1993) 598

[27] F.H. Dalla Torre, D. Klaumunzer, R. Maass, J.F. Loeffler, Acta Mater. 58 (2010) 3742.

[28] Y.Q. Cheng, Z. Han, Y. Li, E. Ma, Phys. Rev. B. 80 (2009) 134115.

[29] F.F. Wu, Z.F. Zhang, F. Jiang, J. Sun, J. Shen, S.X. Mao, Appl. Phys. Lett. 90 (2007) 191909.
[30] F.F. Wu, Z.F. Zhang, J. Shen, S.X. Mao, Acta Mater. 56 (2008) 894.

[31] F.F. Wu, Z.F. Zhang, S.X. Mao, Acta Mater. 57 (2009) 257.

[32] F. Jiang, Y.L. Zhao, L.C. Zhang, S.B. Pan, Y.G. Zhou, L. He, J. Sun, Adv. Eng. Mater. 11 (2009) 177.

[33] A.S. Argon, M. Salama, Mater. Sci. Eng. 23 (1976) 219.

[34] M.Q. Jiang, Z. Linf, J.X. Meng, L.H. Dai, Philos. Mag. 88 (2008) 407

[35] Z. Han, W.F. Wu, Y. Li, Y.J. Wei, H.J. Gao, Acta Mater. 57 (2009) 1367.

[36] Y. Yang, J.C. Ye, J. Lu, P.K. Liaw, C.T. Liu, Appl. Phys. Lett. 96 (2010) 011905

[37] M.Q. Jiang, L.H. Dai, Acta Mater. 59 (2011) 4525.

[38] L.C. Zhang, F. Jiang, Y.L. Zhao, J.F. Zhang, L. He, J. Sun, Mater. Sci. Eng. A 527 (2010) 4122.

[39] H. Bei, S. Xie, E.P. George, Phys. Rev. Lett. 96 (2006) 105503.

[40] A.V. Sergueeva, N.A. Mara, J.D. Kuntz, E.J. Lavernia, A.K. Mukherjee, Philos. Mag. 85 (2005) 2671.

[41] S.X. Song, T.G. Nieh, Intermetallics 19 (2011) 1968-1977.

[42] K.M. Flores, R.H. Dauskardt, Intermetallics 12 (2004) 1025.

[43] R.D. Conner, W.L. Johnson, N.E. Paton, W.D. Nix, J. Appl. Phys. 94 (2003) 904

[44] R. Maaß, D. Klaumunzer, J.F. Loeffler, Acta Mater. 59 (2011) 3205. 